\title{
RESULTADO TARDIO DA INFECÇÃO ISOLADA NO QUADRIL POR PARACOCCIDIOIDES BRASILIENSIS
}

\section{LATE OUTCOME OF PARACOCCIDIOIDES BRASILIENSIS ISOLATED INFECTION ON THE HIP}

\author{
Celso Hermínio Ferraz Picado', Flavio Luis Garcia², Carlos Rafael Rodrigues Marcondes ${ }^{3}$
}

\section{RESUMO}

Infecções causadas pelo Paracoccidioides brasiliensis são sempre um desafio diagnostico mesmo em áreas endêmicas, devidas as suas múltiplas apresentações clinicas e órgãos envolvidos. Este artigo descreve a evolução do único caso descrito na literatura no qual a doença acometeu apenas um quadril.

Descritores: Paracoccidioidomicose; Osteomielite; Quadril.

\section{INTRODUÇÃo}

Paracoccidioidomicose é uma infecção que raramente envolve o aparelho locomotor. A doença é causada pelo Paracoccidioides brasiliensis, e normalmente é negligenciada ou confundida com outras doenças mais freqüentes como neoplasias ou infecções bacterianas.

O objetivo deste trabalho é descrever a evolução do único caso relatado na literatura ${ }^{(1)}$, de paracoccidioidomicose acometendo a articulação do quadril como única manifestação da doença.

\section{RELATO DO CASO}

Paciente com 22 anos, feminino, mulata, trabalhadora rural, refere que há 6 meses iniciou dor progressiva no quadril direito que piorava com a movimentação e a impedia de trabalhar. No exame físico revelava mucosa pálida, hipotrofia da coxa direita, limitação da movimentação o quadril com $100^{\circ}$ de flexão, $0^{\circ}$ de extensão, $30^{\circ}$ de abdução, $15^{\circ}$ de adução, $20^{\circ}$ rotação interna, $20^{\circ}$ rotação externa. Teste de Thomas e Trendelemburg negativos. Não havia nenhum linfonodo palpável ou visceromegalia.

As radiografias da pelve evidenciaram uma lesão lítica bem delimitada na região inferior do colo do fêmur direito invadindo o osso cortical adjacente, ausência de reação peri-

\begin{abstract}
SUMMARY
Infections caused by Paracoccidioides brasiliensis are always a diagnostic challenge, even in endemic areas due to its multiple clinical presentations and involved organs. This paper describes the evolution of the only case found in literature in which the disease affected just one hip.
\end{abstract}

Keywords: Paracoccidioidomycosis; Osteomyelitis; Hip joint.

osteal, redução do espaço articular e achatamento da região superior da cabeça do fêmur (Figura 1). O hemograma estava alterado apresentando anemia $(\mathrm{Hb} 9,5 \mathrm{~g} / \mathrm{dL})$, leucocitose $\left(14.000 / \mathrm{mm}^{3}\right.$ com neutrofilia) e velocidade de hemossedimentação aumentada ( $58 \mathrm{~mm} / \mathrm{h})$. As suspeitas diagnósticas iniciais foram osteomielite subaguda hematogênica ou neoplasia. O exame de ressonância magnética mostrou extensa lesão envolvendo cabeça e colo femorais, com destruição óssea e infiltração dos tecidos moles adjacentes, derrame articular e espessamento da cápsula. Biopsia aspirativa da lesão foi realizada, e a análise histológica revelou fragmentos de tecido fibroconectivo apresentando um processo crônico granulomatoso e uma florida reação de células gigantes. Estruturas aredondadas birefrigentes semelhante a leveduras com característica de esporos do Paracoccidioides brasiliensis foram observadas. Contraimunoeletroforese especifica para paracoccidioidomicose foi positiva para diluições superiores à $1 / 4$.

Nenhum outro exame de investigação complementar (radiografias de tórax, tomografia computadorizada de crânio, tórax e abdômen) detectou outra lesão em qualquer outro órgão. Da mesma forma a cintilografia óssea trifásica com tecnécio (Tc 99m) apenas mostrou aumento da captação do radiofarmaco no quadril direito, sem apresentar nenhu-

Trabalho realizado no Hospital das Clínicas de Ribeirão Preto da Faculdade de Medicina de Ribeirão Preto da Universidade de São Paulo - Departamento de Biomecânica, Medicina e Reabilitação do Aparelho Locomotor.

Endereço para correspondência: Av Bandeirantes, 3900 Ribeirão Preto- São Paulo - e-mail: cfpicado@fmrp.usp.br

1.Professor Doutor do Departamento de Biomecânica, Medicina e Reabilitação do Aparelho Locomotor da Faculdade de Medicina de Ribeirão Preto

2. Médico Assistente do grupo do quadril do Hospital das Clinicas de Ribeirão Preto

3. Médico residente do grupo do quadril do Hospital das Clinicas de Ribeirão Preto

Trabalho recebido em: 21/10/05 aprovado em 02/01/05 
ma outra lesão em qualquer parte do esqueleto, levandonos a concluir que se tratava de uma forma localizada da doença.

O tratamento não cirúrgico foi iniciado com sulfametoxazol 2400mg associado com trimetoprim 480mg diariamente por 2 anos. Após 5 meses de tratamento houve melhora importante dos sintomas da paciente, e a radiografia da pelve demonstrava que a área lítica do colo do fêmur estava parcialmente preenchida por osso, restando apenas diminuição do espaço articular (Figura 2). Após dois anos, quando se deu o término do tratamento medicamentoso, a paciente estava assintomática, a radiogra-

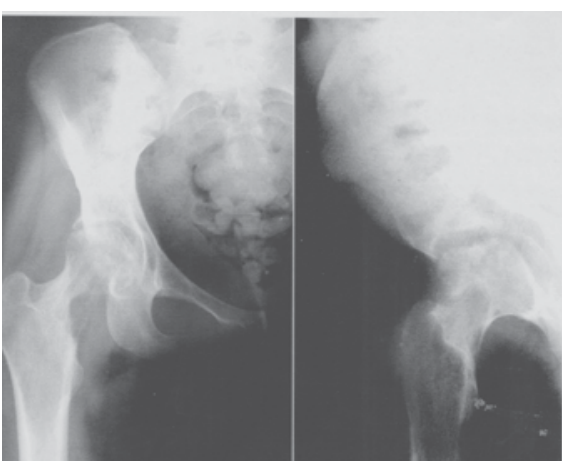

Figura 1 - Radiografia inicial do quadril demonstrando uma lesão lítica na região inferior do colo, e um achatamento na região ântero-superior da cabeça do fêmur.

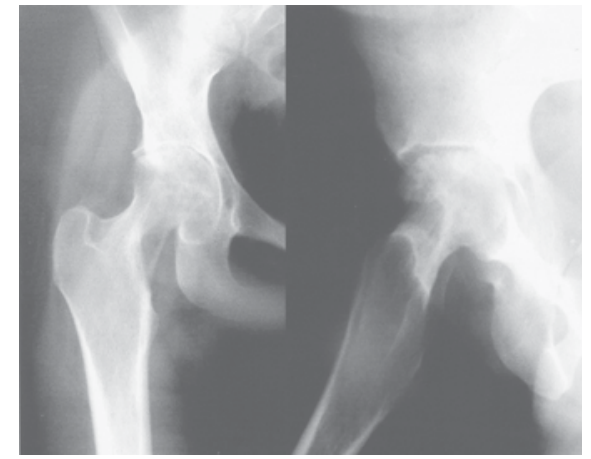

Figura 2 - Radiografia do quadril demonstrado recuperação parcial da lesão do colo femoral e diminuição do espaço articular, com 5 meses de tratamento.

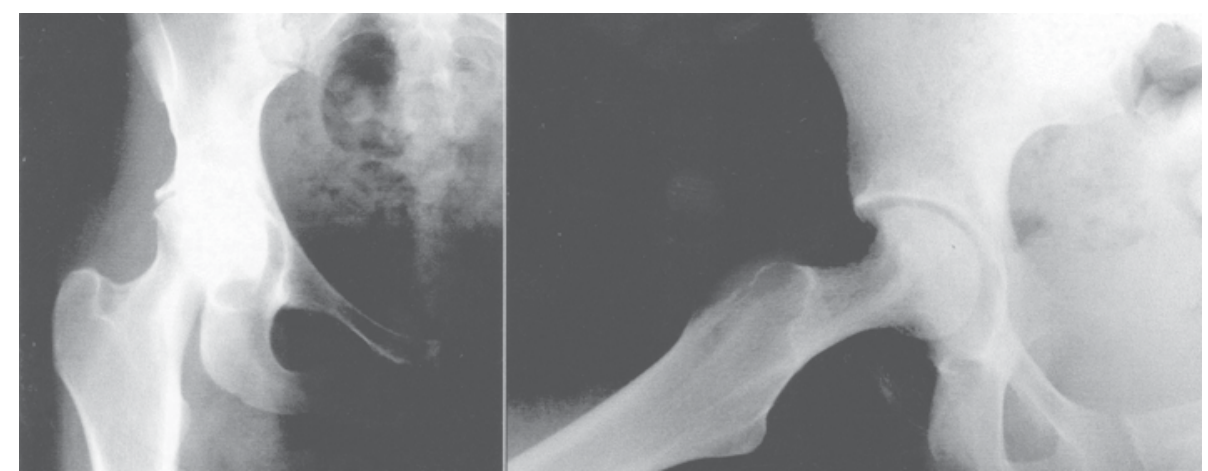

Figura 3 - Radiografias do quadril demonstrando remodelação do colo, retorno da esfericidade da cabeça do fêmur com diminuição do espaço articular após 2 anos de tratamento.

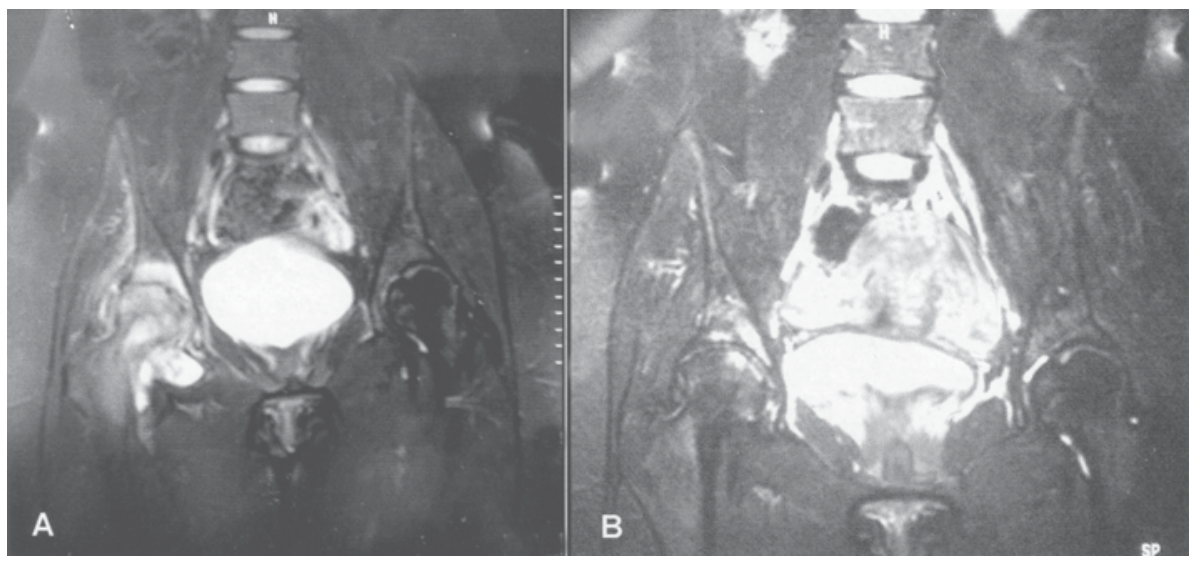

Figura 4 - Imagem de ressonância magnética, tempo T2 com saturação de gordura,(A) pré e (B) pós-tratamento, demonstrando recuperação da lesão com diminuição do edema ósseo, tanto no fêmur como do acetábulo, do derrame articular, e da área lítica na região inferior do colo.

\section{DISCUSSÃO}

A maioria das informações sobre lesões ósteo-articulares causadas pelo Paracoccidioides brasiliensis foram observadas nas formas disseminadas da doença, com múltiplos órgãos envolvidos. Formas isoladas de acometimento ósteo-articular da paracoccidioidomicose são eventos raros e pouco descrito na literatura. Figueiredo et al.(2), em analise de dados obtidos na Medline, Embase and Lilacs no período de 1966 à janeiro de 2001, estudou 345 casos de infecções articulares fungicas, e apenas cinco destas foram causadas pelo Paracoccidioides brasiliensis. Amstalden et al. ${ }^{(3)} \mathrm{pu}$ blicou nove casos de paracoccidioidomicose em que o aparelho locomotor foi a manifestação clínica principal da do- fia da pelve demonstrava remodelação na região do colo do fêmur (Figura 3) e a ressonância magnética comparada com o exame inicial mostrou diminuição do edema ósseo, tanto no acetábulo como no colo e cabeça do fêmur, do derrame articular e da reação nos tecidos moles adjacentes (Figura 4). A contraimunoeletroforese especifica para paracoccidioidomicose estava negativa. ença, e em apenas dois destes casos, um envolvendo o fêmur e outro o cotovelo, não apresentavam qualquer lesão em outro órgão.

O Paracoccidioides brasiliensis é encontrado amplamente no solo da América do Sul e Central. A contaminação ocorre por via inalatória e a maioria dos casos se limita a uma infecção autolimitada no pulmão com pouco ou ne- 
nhum sintoma. Em alguns casos, principalmente em indivíduos imunocomprometidos, pode ocorrer a progressão da doença para infecção crônica pulmonar ou disseminação para outros órgãos como fígado, baço, linfonodos, glândulas adrenais, articulações e osso entre outros.

A aparência radiográfica da lesão óssea é descrita como uma área lítica, bem delimitada, com ou sem bordas escleróticas, que podem ocorrer em qualquer osso, mas que é mais comum de encontrar na clavícula, escapula e coste$\operatorname{las}^{(4,5)}$. Os diagnósticos diferenciais deste tipo de lesão incluem osteomielite bacteriana, tuberculose, linfoma e osteosarcoma ${ }^{(4)}$.

O diagnostico é confirmado ao encontrar o microorganismo, portanto é imperativa a realização de uma biopsia do tecido envolvido. Fulciniti et al. ${ }^{(6)}$ relataram o primeiro caso onde a presença do fungo foi confirmada pela biopsia aspirativa com agulha fina.

O tratamento com anfotericina B é efetivo, porém causa freqüentes complicações como febre, tremores e nefrotoxidade, devendo ser reservado para as formas mais graves da doença ${ }^{(3,7)}$. Sulfametoxazol associado com trimetoprim e o cetoconazol são mais freqüentemente usados, e o tratamento deve durar pelo menos dois anos, segundo a literatura $^{(7)}$. A ausência de fungos em exames de microscopia subseqüentes ou a negativação dos testes de contraimunoeletroforese são importantes parâmetros para avaliar a eficácia do tratamento. Mesmo assim não existem critérios que confirmem a cura do paciente com paracoccidioidomicose. A possibilidade de ocorrência de recidivas ${ }^{(8)}$ justifica o seguimento dos pacientes por longos períodos.

Resumindo, o envolvimento do aparelho locomotor pelo Paracoccidioides brasiliensis como a única manifestação clinica é um evento raro, e poucos ortopedistas têm experiência com este problema, tanto para estabelecer o diagnostico como para realizar o tratamento do paciente. Este fato também é relevante em áreas não endêmicas pois a constante migração de pessoas pode alterar a distribuição territorial das doenças infecciosas. Este relato de caso mostra a evolução do primeiro caso descrito na literatura onde o quadril foi identificado como único local acometido pela doença.

\section{REFERÊNCIAS BIBLIOGRÁFICAS}

1. Picado $\mathrm{CHF}$, Garcia FL, Barbieri $\mathrm{CH}$. Isolated hip infection by Paracoccidioides brasiliensis: a case report. Hip Intern. 2003; 13:193-5.

2. Figueiredo GC, Figueiredo ECQ, Tavares-Neto J. Artrite fúngica: análise secundá ria de dados. Rev Bras Ortop. 2002; 37:259-69.

3. Amstalden EM, Xavier R, Kattapuram SV, Bertolo MB, Swartz MN, Rosenberg AE. Paracoccidioidomycosis of bone and joints. A clinical, radiologic, and pathologic study of 9 cases. Medicine. 1996; 75:213-25

4. Nogueira SA, Guedes AL, Wanke B, Capella S, Rodrigues K, Abreu TF et al.. Osteomyelitis caused by Paracoccidioides brasiliensis in a child from the metropolitan area of Rio de Janeiro. J Trop Pediatr. 2001; 47:311-15.
5. Nanni L, Pereira ICMR. Aspectos radiográficos de paracoccidiodomicose óssea. Radiol Bras. 1988: 21:101-6

6. Fulciniti F, Troncone G, Fazioli F, Vetrani A, Zeppa P, Manco A et al. Osteomyelitis by Paracoccidiodes brasiliensis (South American blastomycosis): cytologic diagnosis on fine-needle aspiration biopsy smears: a case report. Diagn Cytopathol. 1996; 15:442-6.

7. Barbosa W, Daher RR. Blastomicose sul-americana. In: Veronesi R, editor. Doenças infecciosas e Parasitarias. $8^{a}$ ed. Rio de Janeiro: Guanabara-Koogan; 1991.p.634-46. 8. Brummer E, Castaneda E, Restrepo A. Paracoccidioidomycosis: na update. Clin Microbiol Rev. 1993; 6:89-117. 